\title{
BEST ALTERNATIVE MODELS TO INCREASE LOCAL PRODUCT CONSUMPTION
}

\section{Püren Veziroğlu}

Kenan Çiftçi

\author{
Bülent Miran
}

\author{
Faruk Emeksiz
}

\begin{abstract}
A local agricultural product means food grown in places close to the province, country or region that we live in. Consumers' preference of local products will contribute significantly to the farmers' welfare of the areas with high agricultural potential. Within the scope of the study, it has been analyzed under which conditions made consumer tendencies towards local products will turn into behavior of preferring the local products more. The data of the study have been obtained through face to face interviews with agricultural product consumers. Consumers selected randomly from university students in Adana where is the fourth biggest city of Turkey and has a very high potential of agricultural production. Firstly through local product preference model with the aid of AAS (Analytical Network Process) the weights that consumers give to the various criteria and choices have been determined. Based on these weights the combinations of most suitable conditions that consumers will prefer were determined. By taking into consideration the combination of consumers' three conditions with highest probability were examined. In determining the best design, the method of "the best combinations of choices" (BeCA) was employed. BeCA gives optimum homogeneous preference combinations with the aid of $0-1$ programming. The best combinations that were obtained were studied thoroughly with statistical analyses.
\end{abstract}

Keywords: Local Product, Analytical Network Process, The Best Combination Of Choices, Consumer 